\title{
Awareness and knowledge of human papillomavirus vaccination and their influential factors among Chinese women: a systematic review ${ }^{\dagger}$
}

Original article

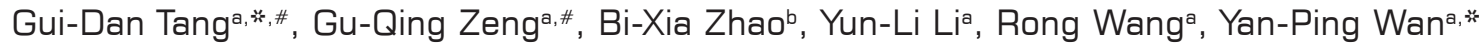

a Institute of Nursing, School of Nursing, University of South China, Hengyang, Hunan 421001, China

${ }^{b}$ Affiliated Nanhua Hospital, University of South China, Hengyang, Hunan 421001, China

Received: 14 August 2018; Accepted: 31 December 2018; Published: 20 December 2019

Abstract: Objectives: To systematically review the knowledge attitudes and the influential factors on human papillomavirus (HPV) vaccination among Chinese women.

Methods: Published studies on knowledge and attitudes of HPV vaccination for preventing cervical cancer among Chinese female population were retrieved using the major Chinese and English databases. Meanwhile, handwork retrieval was also conducted and the references including in the literature were retrieved. The quality of the literature was rigorously evaluated and extracted independently by two researchers and the data were analyzed and described by review manager 5.3 (RevMan5.3) software. Results: In all, 19 articles including 8 articles in Chinese and 11 in English were chosen. A total of 30,176 participants were included and the sample size ranged from 64 to 6,024. The overall awareness of HPV and HPV vaccine among Chinese women was at a low level. Chinese women generally showed poor knowledge about HPV and HPV vaccine. Acceptance of HPV vaccination among Chinese women was at a high level. Vaccination intentions were influenced by the theory of planned behavior (TPB) and measured by attitudes subjective norms and perceived behavioral control.

Conclusions: The health authorities may evaluate and develop TPB-based interventions to increase HPV vaccination intentions of Chinese women. HPV vaccination programs should focus on carrying out multi-level and targeted health education and developing effective public health strategies after balancing the cost and benefit of HPV vaccine program. Medical staff should play the positive role in promoting the use of HPV vaccines in China. Integration of policy and community perspectives and multi-level interventions are essential to maximize the public health benefits of HPV vaccination.

Keywords: awareness • China • human papillomavirus • theory of planned behavior • vaccine $\bullet$ women

(c) Shanxi Medical Periodical Press.

"Gui-Dan Tang and Yan-Ping Wan are co-corresponding authors.

* Gui-Dan Tang and Gu-Qing Zeng are co-first authors and they contributed equally to this study.

${ }^{\dagger}$ This project was supported by Key Project Fund of the Educational Committee of Hunan Province (No. 15A164 No.17A188) and

Outstanding Young Project Fund of the Educational Committee of Hunan Province (No. 16B229).

How to cite this article: Tang GD, Zeng GQ, Zhao BX, Li YL, Wang R, Wan YP. Awareness and knowledge of human papillomavirus vaccination and their influential factors among Chinese women: a systematic review. Front Nurs. 2019; 4: 317-326.

* Corresponding author.

E-mail: dandan112906@yahoo.com (G. -D. Tang); wanyy1991@aliyun.com (Y. -P. Wan)

○ Open Access. @ 2019 Gui-Dan Tang et al., published by Sciendo. (cc) BY-Nc-ND This work is licensed under the Creative Commons Attribution NonCommercial-NoDerivatives 4.0 License. 


\section{Introduction}

Cervical cancer is the second most prevalent cancer and one of the top causes of cancer death worldwide among female. ${ }^{1}$ It is estimated that 98.9 per 100,000 Chinese would be newly diagnosed and about 30.5 per 100,000 Chinese will die from cervical cancer in 2015. ${ }^{2}$ Persistent human papillomavirus (HPV) infection is the primary factor of cervical cancer ${ }^{3,4}$ and HPV vaccines have been recognized by World Health Organization (WHO) as the primary prevention to curb the potential disease process of cervical cancer. Because of the availability of HPV vaccines, cervical cancer has become preventable with the clear cause..$^{5,6}$ Three types of HPV vaccines have been developed. In 2016, the Cervarix was approved in China for use on female aims at preventing genital warts and cervical cancer. But few people know the relationship between HPV and cervical cancer and preventive effect of the vaccine, let alone understanding correctly. Studies have shown that the HPV vaccine will significantly reduce the burden of cervical cancer in combination with other preventive measures particularly. ${ }^{7}$

Theory of planned behavior (TPB) is one of the most influential theoretical models of behavioral research in social psychology. The TPB posits that attitude subjective norms and perceived behavioral control influence behavioral intention and subsequently behavior. Attitude refers to individual positive or negative appraisal of the behavior. Subjective norms refer to the social pressure that an individual perceives for a particular behavior. Perceived behavioral control refers to expecting obstacles to perform the behavior. Additionally, behavioral intentions directly determine behavior.

Therefore, this systematic review aimed to gain a better understanding of the cognition of HPV vaccine and use the TPB to analyze influential factors which are of great importance in identifying concerns and needs for formulating practical public health strategies for Chinese community.

\section{Methods}

\subsection{Searching strategies}

PubMed (Medline), Web of Science, CNKI, Wanfang Data, and CQVIP Data were searched by two researchers from December 2005 to December 2017. This vaccine (Gardasil ${ }^{\mathrm{TM}}$ ) was approved by the FDA in 2006 for use in females aged 9-26 years. To increase the recall rate of literature we set the search time to December 2005. The search terms were "HPV" OR "Human papillomavirus" OR "HPV vaccine" OR "HPV vaccination" OR "cervical cancer vaccine" OR "cervical cancer prevention" AND "acceptance" OR "acceptability" OR "attitude" OR" awareness" OR "beliefs" OR "knowledge" OR "intention" OR "perception" OR "uptake" OR "willing" OR "willingness" AND "Chinese" OR "China" OR "Hong Kong" OR "Taiwan" OR "Taiwanese" OR "Macao" OR "Macau." Meanwhile, manual retrieval was also conducted and the references including in the literature were retrieved.

\subsection{Inclusion and exclusion criteria}

Studies included in this review needed to meet the following criteria: (1) reporting awareness knowledge attitudes acceptances or beliefs toward HPV and HPV vaccine among Chinese female population; (2) studies that were primary researches collecting primary data and published in academic journals; and (3) studies published in either English or Chinese language.

Studies were excluded from this review if they meet the following criteria: (1) Chinese women were not included in sample population or specific results for Chinese women could not be extracted from the overall results; (2) studies that investigated the knowledge and attitudes of male healthcare professionals or students; (3) studies that focused on immunization efficacy or health technology assessment; and (4) reviews on recommendations and health practice guideline.

\subsection{Data extraction and critical appraisal}

Data were extracted into a pre-specified data extraction form by one researcher and checked by another. Information about study design locations targeted sample research question key findings and interpretations was presented (data extraction shown in Tables 1 and 2).

\subsection{Data analysis}

No data were suitable for statistical pooling or metaanalysis because of the large clinical heterogeneity. Instead, the data were only analyzed by descriptive qualitative.

\section{Results}

As shown in Figure 1, 2,840 articles were identified after database searches, 39 were given full-text review with 19 meeting inclusion criteria. ${ }^{8-26}$

\subsection{Study characteristics}

All articles were cross-sectional studies. Regarding study locations, 4 and 13 studies were conducted 


\begin{tabular}{|c|c|c|c|c|c|}
\hline Author & Study design & Age(years) & Sample size & Region in China & Acceptability (\%) \\
\hline Wang et al. $2015^{8}$ & Cross-sectional & $35-48$ & 185 & Jinan & 29.19 \\
\hline Wong et al. $2009^{9}$ & Cross-sectional & $18-20$ & 992 & Hong Kong & 70.80 \\
\hline Kwan et al. $2008^{10}$ & Qualitative-quantitative & $13-20$ & 64 & Hong Kong & 68.80 \\
\hline Yu et al. $2016^{11}$ & Cross-sectional & $30-56$ & 1578 & Weihai & 26.49 \\
\hline Chiang et al. $2016^{12}$ & Cross-sectional & $18-25$ & 234 & Hong Kong & 69.60 \\
\hline Chang et al. $2013^{13}$ & Cross-sectional & $19-47$ & 1703 & the mainland & 81.00 \\
\hline Kwan et al. $2009^{14}$ & Cross-sectional & $>18$ & 1261 & Hong Kong & 88.00 \\
\hline Hsu et al. $2009^{15}$ & Cross-sectional & $17-36$ & 845 & Taiwan & 63.00 \\
\hline Li et al. $2009^{16}$ & Cross-sectional & $14-59$ & 6024 & the mainland & 84.60 \\
\hline Wang et al. $2016^{17}$ & Cross-sectional & $37-48$ & 377 & Taiwan & 78.00 \\
\hline Feng et al. $2012^{18}$ & Cross-sectional & $18-50$ & 1432 & Zhejiang & 65.40 \\
\hline Li et al. $2008^{19}$ & Cross-sectional & $23-45$ & 1013 & Beijing & 75.91 \\
\hline Yan et al. $2013^{20}$ & Cross-sectional & $30-49$ & 1681 & Gansu & 94.23 \\
\hline Wang et al. $2014^{21}$ & Cross-sectional & $23-81$ & 250 & Shaanxi & 82.00 \\
\hline Zhou et al. $2011^{22}$ & Cross-sectional & $23-45$ & 500 & Shanxi & 82.00 \\
\hline Zhao et al. $2010^{23}$ & Cross-sectional & $16-54$ & 997 & Shanghai & 66.10 \\
\hline Wang et al. $2015^{24}$ & Cross-sectional & $21-60$ & 4897 & Shenzhen & 66.00 \\
\hline Su et al. $2016^{25}$ & Cross-sectional & $21-71$ & 973 & Xi'an & 76.00 \\
\hline Ayizuoremu et al. $2015^{26}$ & Cross-sectional & $16-60$ & 3900 & Xinjiang & No mention \\
\hline
\end{tabular}

Table 1. Characteristics of included studies.

\begin{tabular}{|c|c|c|c|}
\hline \multirow[t]{2}{*}{ Author } & \multicolumn{2}{|l|}{ Results } & \multirow[t]{2}{*}{ Measures } \\
\hline & Awareness/attitude & Factors & \\
\hline Wang et al. $2015^{8}$ & $\begin{array}{l}30.3 \% \text { of the participants had heard of HPV and } \\
12.4 \% \text { of them had heard of HPV vaccine }\end{array}$ & $\begin{array}{l}\text { Concerns about safety efficacy } \\
\text { and source of HPV vaccine } \\
\text { Cost }\end{array}$ & $\begin{array}{l}\text { vaccine safety is assured and the cost } \\
\text { is reasonable or subsidized by the } \\
\text { government }\end{array}$ \\
\hline Wong et al. $2009^{9}$ & $\begin{array}{l}89 \% \text { of the participants did not know that HPV } \\
\text { infection could cause cervical cancer }\end{array}$ & $\begin{array}{l}\text { Age } \\
\text { Having had sexual intercourse } \\
\text { Beliefs regarding the } \\
\text { effectiveness of vaccination }\end{array}$ & $\begin{array}{l}\text { More targeted sexual health education } \\
\text { Solving the potential "unknown" } \\
\text { side effects of the vaccine by health } \\
\text { providers }\end{array}$ \\
\hline Kwan et al. $2008^{10}$ & $\begin{array}{l}\text { No participant had any knowledge about HPV } \\
\text { Over half of the participants had heard of } \\
\text { vaccination but no one could provide any } \\
\text { details }\end{array}$ & $\begin{array}{l}\text { High monetary cost } \\
\text { Uncertain length of vaccine } \\
\text { effectiveness } \\
\text { Low perceived risk of HPV } \\
\text { infection } \\
\text { Anticipated family disapproval } \\
\text { Fear of the pain of injection }\end{array}$ & $\begin{array}{l}\text { Providing professional information on } \\
\text { HPV vaccination } \\
\text { Raising perceived need to take } \\
\text { preventive measures against HPV } \\
\text { infection }\end{array}$ \\
\hline Yu et al. $2016^{11}$ & $\begin{array}{l}19.3 \% \text { of the participants had heard of HPV } \\
26.5 \% \text { of them expressed willingness to } \\
\text { vaccination }\end{array}$ & $\begin{array}{l}\text { Age } \\
\text { Education occupation household } \\
\text { income Knowledge level }\end{array}$ & $\begin{array}{l}\text { Appropriate health education } \\
\text { Reasonable price }\end{array}$ \\
\hline Chiang et al. $2016^{12}$ & $\begin{array}{l}69.6 \% \text { of the participants intended to get } \\
\text { vaccinated }\end{array}$ & $\begin{array}{l}\text { Knowledge } \\
\text { Cost }\end{array}$ & $\begin{array}{l}\text { More aggressive education and } \\
\text { promotion activities on HPV and HPV } \\
\text { vaccination }\end{array}$ \\
\hline Chang et al. $2013^{13}$ & $22.7 \%$ of the participants had heard of HPV & $\begin{array}{l}\text { Vaccine's safety } \\
\text { Efficacy } \\
\text { Limited use }\end{array}$ & $\begin{array}{l}\text { Incorporation of lecture-based } \\
\text { education initiative into a government- } \\
\text { sponsored or school-based program }\end{array}$ \\
\hline Kwan et al. $2009^{14}$ & $\begin{array}{l}\text { About } 38 \% \text { of the participants had heard of HPV } \\
50 \% \text { of them had heard of vaccination against } \\
\text { cervical cancer }\end{array}$ & $\begin{array}{l}\text { Misconceptions } \\
\text { A grossly inadequate knowledge } \\
\text { about HPV and HPV vaccination }\end{array}$ & $\begin{array}{l}\text { Culturally sensitive and tailored } \\
\text { education for the public }\end{array}$ \\
\hline Hsu et al. $2009^{15}$ & $\begin{array}{l}\text { Over } 50 \% \text { of the participants were aware of } \\
\text { HPV and the HPV vaccine } \\
63 \% \text { of them reported a high intention to obtain } \\
\text { the HPV vaccine }\end{array}$ & $\begin{array}{l}\text { Demographic factors } \\
\text { Health belief factors predicted } \\
\text { HPV vaccination }\end{array}$ & $\begin{array}{l}\text { Educational campaigns focusing on } \\
\text { the efficacy safety and benefits of the } \\
\text { HPV vaccine }\end{array}$ \\
\hline Li et al. $2009^{16}$ & $\begin{array}{l}\text { Only } 15.0 \% \text { of the participants had heard of } \\
\text { HPV and this knowledge differs between rural } \\
(9.3 \%) \text { and metropolitan areas }(21.6 \%) \\
84.6 \% \text { of the participants were willing to be } \\
\text { vaccinated }\end{array}$ & $\begin{array}{l}\text { Lack of knowledge } \\
\text { Doubts on the source of the HPV } \\
\text { vaccine } \\
\text { Safety }\end{array}$ & $\begin{array}{l}\text { Public health campaign } \\
\text { Government buy-in with commitment } \\
\text { of resources } \\
\text { Affordable vaccines } \\
\text { Establishment of a health infrastructure }\end{array}$ \\
\hline
\end{tabular}

Table 2. (Continued). 


\begin{tabular}{|c|c|c|c|}
\hline \multirow[t]{2}{*}{ Author } & \multicolumn{2}{|l|}{ Results } & \multirow[t]{2}{*}{ Measures } \\
\hline & Awareness/attitude & Factors & \\
\hline Wang et al. $2016^{17}$ & $\begin{array}{l}\text { Half of the participants had heard of HPV } \\
78 \% \text { of the participants reported a high } \\
\text { intention regarding HPV vaccination }\end{array}$ & $\begin{array}{l}\text { Family history of gynecological } \\
\text { tumors } \\
\text { Awareness }\end{array}$ & $\begin{array}{l}\text { Recommendations by physicians and } \\
\text { nurses }\end{array}$ \\
\hline Feng et al. $2012^{18}$ & $\begin{array}{l}39.1 \% \text { of women in urban areas and } 27.1 \% \text { in } \\
\text { rural areas had heard of HPV } \\
23.7 \% \text { and } 15.1 \% \text {, respectively, had heard of } \\
\text { the HPV vaccine }\end{array}$ & $\begin{array}{l}\text { Inadequate knowledge } \\
\text { Misconceptions about HPV }\end{array}$ & $\begin{array}{l}\text { Education campaigns targeting } \\
\text { different populations }\end{array}$ \\
\hline Li et al. $2008^{19}$ & $\begin{array}{l}30.7 \% \text { of the participants had heard of HPV. } \\
51.78 \% \text { of them knew that HPV infection was } \\
\text { related to cervical cancer }\end{array}$ & $\begin{array}{l}\text { Age } \\
\text { Educational level } \\
\text { HPV vaccine's safety and } \\
\text { efficacy }\end{array}$ & Public health education \\
\hline Yan et al. $2013^{20}$ & $\begin{array}{l}94.29 \% \text { of the participants did not know about } \\
\text { HPV at all but } 94.23 \% \text { of them would like to take } \\
\text { HPV vaccine }\end{array}$ & $\begin{array}{l}\text { Lack of perceived risk of cervical } \\
\text { cancer }\end{array}$ & $\begin{array}{l}\text { Spreading HPV and cervical cancer- } \\
\text { related knowledge } \\
\text { Improving quality of life essentially }\end{array}$ \\
\hline Wang et al. $2014^{21}$ & $\begin{array}{l}27.6 \% \text { participants had heard of HPV and } \\
17.6 \% \text { of them had heard of vaccine } \\
82.0 \% \text { of them would like to take HPV vaccine }\end{array}$ & $\begin{array}{l}\text { Occupation } \\
\text { Degree of education } \\
\text { Family income }\end{array}$ & $\begin{array}{l}\text { HPV health education especially for } \\
\text { low level of education of farmers and } \\
\text { workers housewives and low-income } \\
\text { groups }\end{array}$ \\
\hline Zhou et al. $2011^{22}$ & $\begin{array}{l}\text { Only } 11.8 \% \text { of the participants had heard } \\
\text { of HPV } \\
25 \% \text { of them had heard of vaccine }\end{array}$ & $\begin{array}{l}\text { HPV vaccine's safety and } \\
\text { efficacy } \\
\text { Cost }\end{array}$ & $\begin{array}{l}\text { Public health education } \\
\text { Improving scope of effective medical } \\
\text { insurance }\end{array}$ \\
\hline Zhao et al. $2010^{23}$ & $20.6 \%$ of the participants had heard of HPV & $\begin{array}{l}\text { Low perception of HPV infection } \\
\text { Vaccine's limited use } \\
\text { Source of HPV vaccine }\end{array}$ & Health education at all levels \\
\hline Wang et al. $2015^{24}$ & $\begin{array}{l}46.1 \% \text { of the participants had heard of HPV. } \\
28.8 \% \text { of them had heard of vaccine } \\
66.0 \% \text { of participants were willing to vaccination }\end{array}$ & $\begin{array}{l}\text { Safety of HPV vaccine } \\
\text { Vaccine's limited use in China } \\
\text { Price of HPV vaccine }\end{array}$ & $\begin{array}{l}\text { Targeted education on HPV and HPV } \\
\text { vaccination }\end{array}$ \\
\hline Su et al. $2016^{25}$ & $\begin{array}{l}32.5 \% \text { of the women had ever heard of HPV } \\
76.0 \% \text { of the participants showed willingness to } \\
\text { accept HPV vaccination }\end{array}$ & $\begin{array}{l}\text { Concerns on HPV infection } \\
\text { Occupation } \\
\text { Degree of education }\end{array}$ & $\begin{array}{l}\text { Strengthening public health education } \\
\text { Disseminating information about HPV } \\
\text { vaccine }\end{array}$ \\
\hline $\begin{array}{l}\text { Ayizuoremu et al. } \\
2015^{26}\end{array}$ & $\begin{array}{l}\text { The awareness rates of cervical cancer HPV } \\
\text { and HPV vaccine were } 25.0 \% 8.0 \% \text { and } 4.0 \% \\
\text { among Uygur women and } 35.0 \% 19.0 \% \text { and } \\
7.0 \% \text { among Han women }\end{array}$ & Educational level & $\begin{array}{l}\text { The popularization of knowledge on } \\
\text { HPV and HPV vaccination }\end{array}$ \\
\hline
\end{tabular}

Table 2. Extraction of study contents.

in Hong Kong, China and Mainland China, respectively. The rest two studies were from Taiwan, China. Eleven and eight articles were, respectively, published in English and Chinese. In all, 17 studies only used quantitative survey methodology..$^{8,9,11-26}$ The rest used a qualitative-quantitative approach and conducted by focus group discussions. A supplementary questionnaire was administered to participants before and after group discussion to assess their knowledge attitudes and intention. ${ }^{10}$

The majority of studies used random or cluster sampling methods. ${ }^{8,9,11-14,16,18-20,23-26}$ Two studies in Taiwan, China used convenient sampling, ${ }^{15,17}$ a study in Hong Kong, China used purposive sampling, ${ }^{10}$ a study in Shanxi Province used systematic sampling, ${ }^{22}$ while another study did not mention the methods of conducting survey. ${ }^{21}$

There were 30,176 participants in this review and the sample sizes ranged from 64 to 6,024 . The target participants of all studies were women. The age of the participant ranged from 13- to 71-years old and the most of the participants were above 18 years old.

\subsection{Awareness of HPV and HPV vaccine}

Awareness of HPV was assessed by asking if the participants had heard of HPV in 18 studies. ${ }^{8,10,11,13-26}$ The overall awareness of HPV among Chinese women was at a low level. A study in Gansu Province, an area with high incidence of cervical cancer, showed that $94.3 \%$ of women had not heard of HPV and only $2.4 \%$ of women had known that HPV was linked to cervical cancer. ${ }^{21}$ In Zhejiang Province, $39.1 \%$ of participants in urban areas and $27.1 \%$ of participants in rural areas had heard of HPV. ${ }^{19}$ While the awareness rates of HPV were $8.0 \%$ among Uygur women and $19.0 \%$ among Han women in Xinjiang Uygur Autonomous Region. ${ }^{26}$ Based on the findings of studies, in a rural area in Shanxi Province only $11.8 \%$ of women had heard of $\mathrm{HPV},{ }^{23}$ which was far below the economically developed urban areas in 


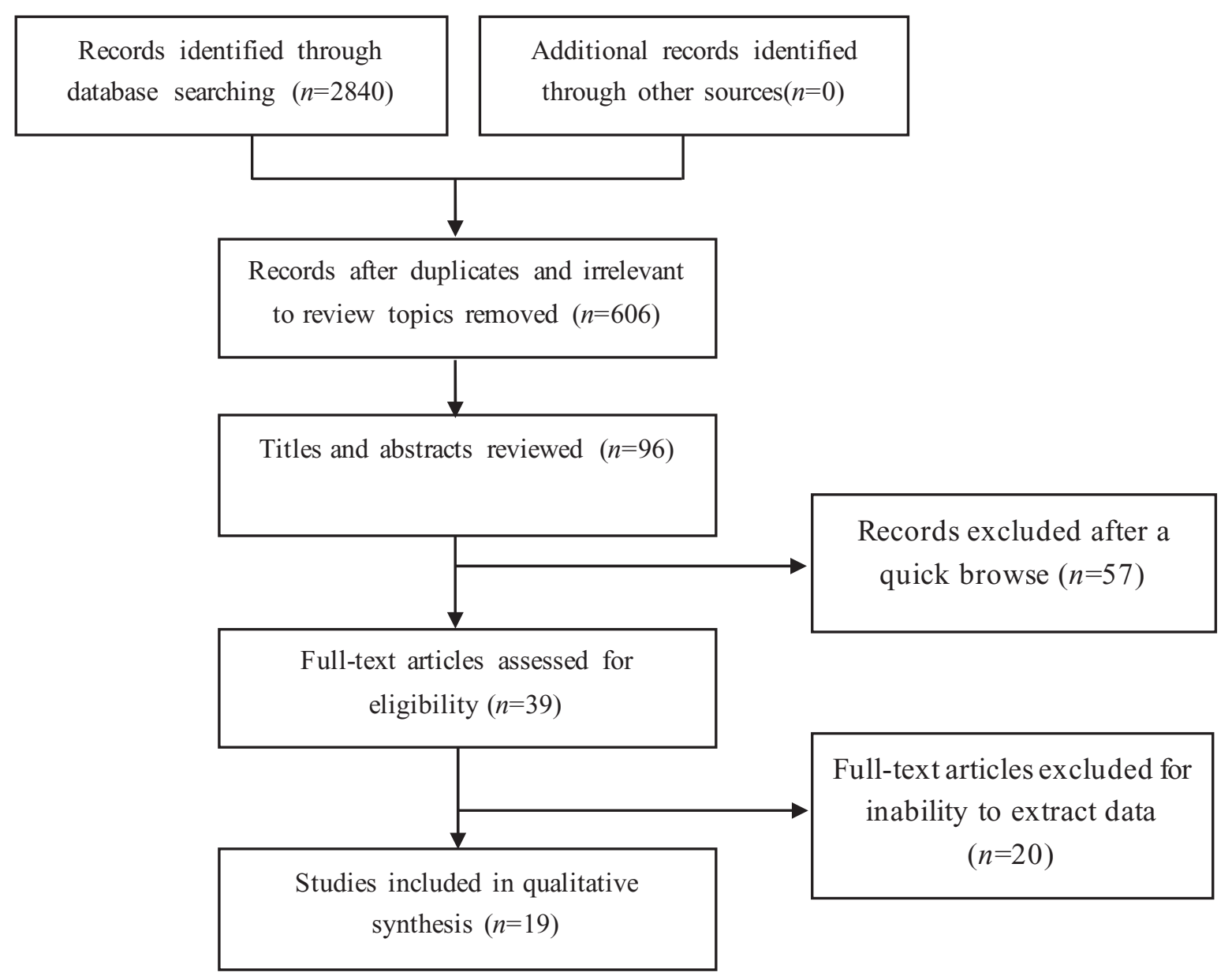

Figure 1. Selection of articles for inclusion in the systematic review after a search conducted in December 2017.

China $(46.9 \%){ }^{25}$ Significant difference on the awareness of HPV was shown between urban and rural areas in China.

Similarly, awareness of HPV vaccine was assessed by asking if the participants had heard of anti-cervical cancer vaccine or HPV vaccine in ten studies. $8,10,11,14,15,18,21,22,24,26$ More than half of participants in Hong Kong, China and Taiwan, China studies indicated that they had heard of HPV vaccine..$^{10,14,15}$ Only $5.5 \%$ of participants in Xinjiang Uygur Autonomous Region ${ }^{26}$ had heard of HPV vaccine. The awareness of HPV vaccine was relatively lower in mainland China than those in Hong Kong, China and Taiwan, China.

\subsection{TPB constructs}

\subsubsection{Attitudes}

Most Chinese women had a positive attitude toward vaccination. A majority of studies reported individual HPV vaccine acceptability. Vaccination acceptance varied depending on the demographic characteristics of the participants but the rate of overall acceptance was high. In Gansu province, the rate of participants accepting HPV vaccination was $94.2 \% .^{20}$ Six studies demonstrated great improvements on the acceptability of HPV vaccination after education intervention. ${ }^{10,11,13,19,20,22}$

Generally, most women showed strong willingness when they were reminded that HPV vaccine could prevent cervical cancer. Swarnapriya et al. reported that vaccine effectiveness was the most important attribute of vaccination. ${ }^{27}$ In Beijing, 96.8\% participants were willing to vaccinate because of its benefits. ${ }^{19}$ In Taiwan, China, women with stronger beliefs of their susceptibility for cervical cancer and the disease severity were more likely to obtain the HPV vaccine. ${ }^{15}$

\subsubsection{Subjective norms}

Subjective norms were predominant factors in participants' intentions. Recommendations from significant 
others such as parents friends and healthcare providers influenced the Chinese women's decision to consider vaccination. In Taiwan, China, the greatest relation to intention was subjective norms which explained $60 \%$ of the variance in parental intention. ${ }^{17}$ It was reported in four studies that the participants would more likely to receive the vaccine after recommendations from healthcare professional and hospital lectures. ${ }^{10,15,20,23}$ In Shandong Province, most parents (81.0\%) hoped HPV vaccine should be included in the expanded program immunization. ${ }^{8}$ Similarly, women in both urban and rural areas believed that the government and healthcare organizations' recognition and attention were important. ${ }^{20,23}$

\subsubsection{Perceived behavioral control}

Cost was an important barrier for HPV vaccination. Some participants thought the vaccine should be free; while others indicated a minority willing to pay some amount although much less than the market price. ${ }^{8,19-26}$ Parents were able to determine whether to endorse the HPV vaccine for their daughters. Mothers mainly worried that acceptance of the vaccine may be seen as an admission of risky or early sexual behavior by her daughter..$^{9,18}$ Young women worried that vaccination would give others the impression that they were sexually active..$^{9,28}$ A previous research in the Gaborone also revealed that participants were more likely to be vaccinated when they were involved in decision-making. ${ }^{29}$ In addition, uncertainties on efficacy or safety of HPV vaccine was another important barrier for the uptakes of HPV vaccines. They worried about the potential side effects of HPV vaccine and duration of vaccine effectiveness. ${ }^{13,14,19,22,23}$ The source of vaccine was also a concern. The majority of Chinese women indicated that they preferred vaccines provided by government or medical institutions. ${ }^{19,20}$

\subsection{Other influential factors for acceptance of HPV vaccination}

\subsubsection{Parental education level and family income}

Women with different educational levels had significant differences in awareness and vaccination willingness. The higher education they had the more they were willing to vaccinate. Participants' willingness with university and above qualifications was up to $74.4 \% .{ }^{23}$ Five studies reported significant association between family income and vaccine willingness. It was found that higher family income was a significant predictor of vaccine willingness. ${ }^{8,11,20,21,24}$

\subsubsection{Sexual behavior}

Among women whether or not they had sexual intercourse age of sexual onset number of sexual partners and preferred ways of contraception were important factors influencing HPV vaccination. Majority of the participants believed that sexually active women or women with multiple sexual partners should be vaccinated. ${ }^{10,15,17}$ In Hong Kong, China, $86 \%$ of the participants agreed with vaccinating sexually active women. ${ }^{14}$ Some participants believed that people with only one sexual partner had a low risk of getting infected with HPV and need not vaccinate. ${ }^{12}$ The findings indicated that existing misconception on risk perception of cervical cancer was common among Chinese women.

\subsubsection{Family history of gynecological tumors or infections}

Family health history was related to women's willingness to receive the HPV vaccine. In Taiwan, China, the women with a personal or family history of gynecological tumors or infection were reported they had a high intention to vaccinate. ${ }^{15,17}$ In mainland China, HPV vaccine for preventing HPV infection and sexually transmitted disease was the primary cause of vaccination. Of participants in Gansu Province, 73.6\% women feared that they would suffer from cervical cancer if they had not vaccinated. ${ }^{23}$

\section{Discussion}

\subsection{Knowledge and attitudes toward HPV vaccine}

Previous studies on HPV vaccines were mainly concentrated in many Western and a number of Asian countries. However, studies on Chinese participants particularly were limited. Therefore, the purpose of this systematic review was to investigate the knowledge attitudes and the influential factors for HPV vaccination among Chinese women which was necessary for promotion and use of vaccines. Women's knowledge and attitudes in China were influenced by different social demographic backgrounds. HPV vaccine has been licensed in Hong Kong, China and Taiwan, China since October 2006. It was a good news that Cervarix and Gardasil were approved in 2016 and 2017, respectively, in mainland China. The awareness of HPV vaccine was relatively lower in mainland China than those in Hong Kong, China and Taiwan, China because of less access to HPV vaccines.

Awareness of HPV and vaccines was one of the potential factors influencing the willingness 
to vaccinate. ${ }^{30}$ Galbraith et al. found that AfricanAmericans and Latinos' willingness to HPV vaccination were much lower than white Americans' willingness because of little knowledge. ${ }^{31}$ The rate of awareness of HPV and vaccine in Italian teenagers was $92 \% .^{32}$ The government achieved high rate of vaccination uptake and completion depending on the integration between the public health and schooling systems which was up to $97.2 \%$ in Brazil. ${ }^{33}$ To raise public awareness and knowledge of HPV and vaccine were important indicators in preventing cervical cancer. However, previous studies indicated that Chinese women's overall knowledge on HPV and HPV vaccine was poor. Most women failed to identify the relationship between HPV infection and cervical cancer and had many misconceptions concerning cervical cancer HPV and HPV vaccine. In contrast, an average of $50 \%$ women in Korea was able to identify correctly the link between HPV and cervical cancer. ${ }^{34}$

Despite lack of knowledge of HPV, the rate of acceptance of HPV vaccine among Chinese women was high. The results of low level of knowledge but high acceptance were similar to the outcomes of a study done in Haitian in 2014 when the HPV vaccine has just been approved. ${ }^{35}$ In fact, many participants had never been exposed to cervical cancer HPV and HPV vaccines before the survey. They may be difficult to make informed decisions about HPV vaccination so it is necessary to raise public awareness by further health education. The studies showed significant improvement in both level of knowledge and acceptance after education intervention; and these results were consistent with Western studies. ${ }^{33}$ Utility of information pamphlet and implementation of mass public health education on HPV vaccine are effective means for promotion and application of vaccination. For ethnic minorities, it should be considered that their mastery of Chinese Putonghua and the promotional materials are available in minority languages and Chinese Putonghua.

\subsection{Influential factors for acceptance of HPV vaccination}

Studies showed parental educational level and family income were associated with awareness and willingness of HPV vaccine. Women with higher level of education may take the initiative to learn the relevant knowledge and had a higher level of acceptance to health knowledge and new things. So women with higher level of education may have a relatively higher acceptance. Vaccination willingness rates were much higher among women living in wealthier families than those among women living in poorer families. There was a positive correlation between vaccination rates and higher family income in the United States. ${ }^{36}$ This was consistent with
Kester et al. ${ }^{37}$ who reported that vaccination coverage of young people in low-income families decreased significantly in the same year.

Being vulnerable to a health problem played a role in motivation for health behaviors. ${ }^{38}$ Similar to the findings from Taiwan, China, parental intention to daughters' HPV vaccination was related to personal history of sexually transmitted diseases or family history of gynecologic tumors in Sweden. ${ }^{39}$ Women expressed a trust in vaccine recommendations from authorities and experts. If the HPV vaccine had been administered to adolescent girls during any healthcare visit in which they received another vaccine, the initiation rates for HPV vaccination in the United States would exceed $90 \%$ among this population. ${ }^{40}$ Physician's recommendation for HPV vaccination was significantly associated with vaccination among females in Louisiana and Alabama. ${ }^{41}$ Those underlined the importance of healthcare professionals as key persons in spreading information about HPV and HPV vaccine. Although healthcare professionals had high level of awareness of HPV infection, they were lack of more comprehensive knowledge of HPV vaccine in mainland China. ${ }^{42}$ Thus, increasing HPV vaccination detailed knowledge and improving positive attitude of healthcare professionals are essential for enhancing the uptakes of HPV vaccines.

HPV vaccines were considered to prevent some sexually transmitted diseases by adolescents in the United States. ${ }^{43}$ Young adults might be reluctant to receive the HPV vaccine because they were afraid of being labeled sexually active. ${ }^{28}$ At the same time, Jumaan et al. found that focusing messages on cervical cancer protection rather than sexually transmitted diseases prevention appeared to help minimize sensitivities around girls' sexuality. ${ }^{44}$ Some participants noted that those who frequently had sex or promiscuity needed vaccine and people who had only one sexual partner had a low risk of becoming infected with HPV. ${ }^{10,14,18,38,42}$ The most frequent reason for not accepting vaccination cited by mothers was 'My daughter is too young to have sex'. Under the influence of traditional Chinese culture, sex has been a sensitive topic and sexually transmitted disease is a sexual stigma which is associated with immorality and infidelity. These findings were similar to the previous study in China that cultural issues such as modesty and embarrassment contributed to low cervical screening attendance. ${ }^{45}$ Health promotion should target at increasing women who have low perceived risk of HPV infection or a fear of social stigma. Public health services for Chinese women need to ensure that the philosophy of the staff and the approach used are culturally relevant especially for culturally sensitive women.

Suspicion of safety and efficacy of the vaccine were reported in some studies as the primary reason 
for refusing vaccination. Participants concerns about the possibility of lasting health problems. . $^{8,9,13,14,19,20}$ The study in the USA comparing parental responses over time found that more cited safety concerns as a reason for not vaccinating their adolescents in 2010 than that in $2008 .^{46}$ In fact, many clinical trials demonstrated that HPV vaccines had a promising effectiveness against cervical cancer and the risk of adverse events related to vaccination were acceptable. The vaccines have been already licensed in many countries. ${ }^{47}$ A survey in Japan showed that a hypothetical restart of a governmental recommendation for the vaccine would induce $4.1 \%$ of all the mothers who were more likely to encourage their daughters to get vaccinated without any other preconditions. ${ }^{48}$ Together, health authorities and mainstream media should spread the impartial and accurate messages to the public and guarantee the safety of HPV vaccines. If possible, the vaccines should be supplied through government programs. It is rise to make medical staff play the positive role in promoting the use of HPV vaccines.

The cost presented a significant barrier to implementation in China. It was found that more than $50 \%$ participants could not afford the HPV vaccines and wanted the government to pay all or part of the costs. A huge gap between affordable price and actual price inevitably leaded to a decline in vaccination rates. We can learn from the Global Alliance for Vaccines and Immunization (GAVI) policy in low- and middle-income countries which made a great success. ${ }^{49}$ It can be considered that cost is shared among recipients government public health insurance companies charities international health organization and pharmaceutical companies. To lower the price of HPV vaccine to an acceptable level, the integration of an appropriately expanded coverage of health insurance and a reasonable cost-sharing mechanism should be conducted.

\subsection{Limitations}

In 18 studies on knowledge and acceptance of HPV and HPV vaccine, the results were inconsistent. Study designs, sample sizes, sampling techniques, sociodemographic characteristics of population measures, and locations may result in the low comparability. Owing to disparities in wealth and unequal development among cities, the results may not accurately represent the knowledge and attitudes of Chinese women in general. Most studies used convenience sampling methods so that samples were not representative. Altogether, sampling among different geographic regions should be stratified based on population density and development in future researches. The assessment and outcome measures differed greatly across the studies and comparability was limited. All studies used a self-administered questionnaire and seven articles did not report the source of measures or questionnaires. ${ }^{19-26}$ Only a study in Taiwan, China tested the ease of reading and clarity of self-administrated questionnaire prior to the survey. ${ }^{15}$ Therefore, appropriate measures should be developed and the literacy level of participants should be assessed so as to obtain accurate data.

\section{Conclusions}

Cervical cancer is posing a big burden on Chinese women and can be preventable by the use of HPV vaccines. HPV vaccines were approved in 2016 and Chinese women have started to getting vaccinated. High HPV vaccination coverage is influenced by individual knowledge and attitudes. This review showed that the overall awareness and knowledge of Chinese women were very low. Raising the awareness and knowledge of Chinese women is extremely urgent. It must make an all-out effort to carry out multi-level and targeted health education but it should be careful to culturally sensitive people. Some major factors influenced the attitudes of HPV vaccination such as cost concerns on efficacy and safety of HPV vaccine recommendations from others and so on. The Health authorities may evaluate and develop TPB-based interventions to increase acceptance of Chinese women after considering all factors. Policymaker should seriously consider to developing effective public health strategies after balancing the cost and benefit of HPV vaccine program. It is necessary to expand the scope of medical insurance coverage and strengthen grass-roots healthcare project construction. Meanwhile, medical staffs should play a positive role in the recommendation of HPV vaccine. Together, all measures can maximize the public health benefits of HPV vaccination.

\section{Acknowledgment}

We would like to acknowledge the helpful comments provided by librarians.

\section{Ethics approval}

The study protocol was approved by the Ethics Committee of University of South China. Potential participants received information about the study and they were informed that their response will be considered an informed consent to participate in the survey. Consent for interviews was also obtained.

\section{Conflicts of interest}

All contributing authors declare no conflicts of interest. 
1. Torre LA, Freddie B, Siegel RL, Ferlay J, LortetTieulent J, Jemal A. Global cancer statistics 2012. CA Cancer J Clin. 2015;65:87-108.

2. Chen WQ, Zheng RS, Peter DB, et al. Cancer statistics in China 2015. CA Cancer J Clin. 2016;66:115-132.

3. Brown DR, Shew ML, Qadadri B, et al. A longitudinal study of genital human papillomavirus infection in a cohort of closely followed adolescent women. J Infect Dis. 2005;191:182-192.

4. Bosch FX, Lorincz A, Munoz N, Meijer CJ, Shah $\mathrm{KV}$. The causal relation between human papillomavirus and cervical cancer. J Clin Pathol. 2002; 55:244-265.

5. Bailey HH, Chuang LT, DuPont NC, et al. American society of clinical oncology statement: human papillomavirus vaccination for cancer prevention. J Clin Oncol. 2016;34:1803-1812.

6. Deleré Y, Wichmann O, Klug SJ, et al. The efficacy and duration of vaccine protection against human papillomavirus: a systematic review and metaanalysis. Dtsch Ärzteblatt Int. 2014;111:584-591.

7. Setiawan D, Oktora MP, Hutubessy R, et al. The health-economic studies of HPV vaccination in Southeast Asian countries: a systematic review. Expert Rev Vaccines. 2017;16:933-943.

8. Wang W, Ma Y, Wang X, et al. Acceptability of human papillomavirus vaccine among parents of junior middle school students in Jinan China. Vaccine. 2015;33:2570-2576.

9. Wong WC, Fong B, Chan PK. Acceptance of human papillomavirus vaccination among first year female university students in Hong Kong. Sex Health. 2009;6:264-271.

10. Kwan TT, Chan KK, Yip AM, et al. Barriers and facilitators to human papillomavirus vaccination among Chinese adolescent girls in Hong Kong: a qualitative-quantitative study. Sex Transm Infect. 2008;84:227-232.

11. $\mathrm{Yu} Y, \mathrm{Xu} M$, Sun J, et al. Human papillomavirus infection and vaccination: awareness and knowledge of HPV and acceptability of HPV vaccine among mothers of teenage daughters in Weihai Shandong China. PLoS One. 2016;11:e0146741.

12. Chiang VC, Wong HT, Yeung PC, et al. Attitude acceptability and knowledge of HPV vaccination among local university students in Hong Kong. Int J Environ Res Public Health. 2016;13:486-501.

13. Chang IJ, Huang R, He W, et al. Effect of an educational intervention on HPV knowledge and vaccine attitudes among urban employed women and female undergraduate students in China: a cross-sectional study. BMC Public Health. 2013;13:916-923.

14. Kwan TT, Chan KK, Yip AM, et al. Acceptability of human papillomavirus vaccination among Chinese women: concerns and implications. BJOG. 2009;116:501-510.

15. Hsu YY, Fetzer SJ, Hsu KF, Chang YY, Huang CP, Chou $\mathrm{CY}$. Intention to obtain human papillomavirus vaccination among Taiwanese undergraduate women. Sex Transm Dis. 2009;36:686-692.

16. Li J, Li LK, Ma JF, et al. Knowledge and attitudes about human papillomavirus (HPV) and HPV vaccines among women living in metropolitan and rural regions of China. Vaccine. 2009;27:1210-1215.

17. Wang MC, Chou CY, Ma MC, Hsu YY. Parental intention regarding the administration of the HPV vaccine for adolescent daughters in Taiwan. Women Health. 2016;56:361-375.

18. Feng S, Xu X, Jin Y, Yao X. Women's knowledge of human papillomavirus (HPV) and their attitudes toward HPV vaccine: preparing for HPV vaccination in China. Asia Pac J Public Health. 2012;24:522-531.

19. Li J, Tu Z, Zhao C, et al. An investigation of HPV prevalence among women living in Beijing and their cognition and attitude toward HPV and HPV vaccine. China Cancer. 2008;17:168-172 (in Chinese).

20. Yan J, Wang XL, Wang XH. Survey on cognition of HPV vaccine among women living in high prevalence area of cervical cancer in Gansu Province. Chin J Health Educ. 2013;29:913-916 (in Chinese).

21. Wang X, Lei SY, Zhu GH, Ma M, Zhao LL. Analysis on cognition and attitude of patients with cervical cancer toward human papillomavirus (HPV) and HPV vaccine. Chin Nurs Res. 2014;28:1589-1591 (in Chinese).

22. Zhou Y, Feng XX, Li ZF, Zhao FH, Qiao YL. Investigation and analysis on the cognition of female in rural area of Shanxi Province toward human papillomavirus and HPV vaccine. Chin J Health Manage. 2011;5:158-159 (in Chinese).

23. Zhao DJ, Gong XZ, Hu ZG, et al. Investigation on the cognitive level of women in community of Shanghai toward human papillomavirus and vaccine. Chin J Biol. 2010;23:558-560 (in Chinese).

24. Wang YY, Zhang YR, Yuan SX, Peng J, Liu ZH. Awareness of HPV vaccine and willingness of vaccination among Shenzhen women. China Cancer. 2015;24:985-989 (in Chinese).

25. Su Q, Yang J, Cheng YM, Xu LJ. Knowledge about HPV and HPV vaccine among outpatients in Xi'an 
city. Chin J Reprod Health. 2016;27:311-314 (in Chinese).

26. Ayizuoremu M, Sayipujiamali M, Guo GL, et al. Investigation and analysis on cognition of cervical cancer HPV and HPV vaccine among Uygur and Han women in Xinjiang. Matern Child Health Care China. 2015;30:434-437 (in Chinese).

27. Swarnapriya K, Kavitha D. Knowledge attitude and practices regarding HPV vaccination among medical and para medical in students India a cross sectional study. Asian Pac J Cancer Prev. 2015;16:8473-8477.

28. Wong LP. Young multiethnic women's attitudes toward the HPV vaccine and HPV vaccination. Int $J$ Gynaecol Obstet. 2008;103:131-135.

29. DiAngi YT, Panozzo CA, Ramogola-Masire D, Steenhoff AP, Brewer NT. A cross-sectional study of HPV vaccine acceptability in Gaborone Botswana. PLoS One. 2011;6:e25481.

30. Do YK, Wong KY. Awareness and acceptability of human papillomavirus vaccine: an application of the instrumental variables bivariate probit model. BMC Public Health. 2012;12:31.

31. Galbraith KV, Chuga JL, Jenerette CM, Moore LA, Palmer $\mathrm{MH}$, Hamilton JB. Parental acceptance and uptake of the HPV vaccine among African-Americans and Latinos in the United States: a literature review. Soc Sci Med. 2016;159:116-126.

32. Sopracordevole F, Cigolot F, Gardonio V, Di Giuseppe J, Boselli F, Ciavattini A. Teenagers' knowledge about HPV infection and HPV vaccination in the first year of the public vaccination programme. Eur J Clin Microbiol Infect Dis. 2012;31:2319-2325.

33. Fregnani JH, Carvalho AL, Eluf-Neto J, et al. A school-based human papillomavirus vaccination program in Barretos Brazil: final results of a demonstrative study. PLoS One. 2013;8:e62647.

34. Lee KN, Chang KH, Cho SS, Park SH, Park ST. Attitudes regarding HPV vaccinations of children among mothers with adolescent daughters in Korea. J Korean Med Sci. 2017;32:130-134.

35. Gichane MW, Calo WA, McCarthy SH, Walmer KA, Boggan JC, Brewer NT. Human papillomavirus awareness in Haiti: preparing for a national HPV vaccination program. J Pediatr Adolesc Gynecol. 2017;30:96-101.

36. Polonijo AN, Carpiano RM. Social inequalities in adolescent human papillomavirus (HPV) vaccination: a test of fundamental cause theory. Soc Sci Med. 2013;82:115-125.

37. Kester LM, Zimet GD, Fortenberry JD, Kahn JA, Shew ML. A national study of HPV vaccination of adolescent girls: rates predictors and reasons for non-vaccination. Matern Child Health J. 2013;17:879-885.

38. Rosenstock IM, Strecher VJ, Becker MH. Social learning theory and the health belief model. Health Educ Behav. 1988;15:175-183.

39. Gottvall M, Grandahl M, Hoglund AT, et al. Trust versus concerns-how parents reason when they accept HPV vaccination for their young daughter. Ups J Med Sci. 2013;118:263-270.

40. Stokley S, Jeyarajah J, Yankey D, et al. Human papillomavirus vaccination coverage among adolescents 2007-2013 and postlicensure vaccine safety monitoring 2006-2014 - United States. Morb Mortal Wkly Rep. 2013;62:620-624.

41. Pierre-Victor D, Trepka MJ, Page TF, Li T, Stephens DP, Madhivanan P. Impact of Louisiana's HPV vaccine awareness policy on HPV vaccination among 13- to 17-year-old females. Health Educ Behav. 2017;44:548-558.

42. Ma $D$, Qiu $H$, Wang $H X$, et al. Investigation on the cognition and acceptability of medical personnel to human papillomavirus and its vaccine in a hospital of Tangshan city. Matern Child Health Care China. 2012;27:397-400.

43. Berenson $A B$. an update on barriers to adolescent human papillomavirus vaccination in the USA. Expert Rev Vaccines. 2015;14:1377-1384.

44. Jumaan $A O$, Ghanem S, Taher J, Braikat M, Al Awaidy S, Dbaibo GS. Prospects and challenges in the introduction of human papillomavirus vaccines in the extended Middle East and North Africa region. Vaccine. 2013;31:G58-G64.

45. Holroyd E, Twinn S, Adab P. Socio-cultural influences on Chinese women's attendance for cervical screening. J Adv Nurs. 2004;46:42-52.

46. Darden PM, Thompson DM, Roberts JR, et al. Reasons for not vaccinating adolescents: National Immunization Survey of Teens 2008-2010. Pediatrics. 2013;131:645-651.

47. Setiawan D, Luttjeboer J, Pouwels KB, Wilschut JC, Postma MJ. Immunogenicity and safety of human papillomavirus (HPV) vaccination in Asian populations from six countries: a meta-analysis. Jpn J Clin Oncol. 2017;47:265-276.

48. Yagi A, Ueda Y, Egawa-Takata T, et al. Development of an efficient strategy to improve HPV immunization coverage in Japan. BMC Public Health. 2016;16:1013.

49. Levin A, Wang SA, Levin C, Tsu V, Hutubessy R. Costs of introducing and delivering HPV vaccines in low and lower middle income countries: inputs for GAVI policy on introduction grant support to countries. PLoS One. 2014;9:e10114. 